\title{
CHAETETID SKELETONS AS SHORT-TERM RECORDS OF PHYSICAL DISTURBANCE EVENTS
}

\author{
MILLER*, Keith B., and WEST, Ronald R., Department of Geology, Kansas State \\ University, Manhattan, Kansas 66506-3201 U.S.A.
}

The growth records of spongiomorph and colonial skeletons have great potential for revealing the short-term depositional dynamics of ancient shallow marine environments. The utility of such skeletons for understanding the type and frequency of physical disturbance is illustrated by chaetetid-bearing limestones from Pennsylvanian (Desmoinesian) cyclothems of southeastern Kansas. Individual chaetetids frequently contain growth-interruption surfaces that are marked by clay partings or encrusting overgrowths of epibionts. Such interruptions occur irrespective of the growth form of the chaetetids, although they are more conspicuous in laminar and domical growth forms with ragged margins. Growth forms with smooth margins and fewer interruptions are more commonly high domical to columnar. The latter occur in cleaner carbonates with higher rates of carbonate accumulation and little siliciclastic influx.

Interruption surfaces, which may be accompanied by reorientation of skeletal growth, record significant depositional and erosive events during the life history of the chaetetids. Similar surfaces have been described from a variety of other organisms including stromotoporoids, fistuliporoid and trepostome bryozoans, and favositid corals. In most environments, physical disturbance events of this time scale are invariably destroyed by subsequent bioturbation or current reworking. For this reason, chaetetid skeletons provide a valuable means of inferring the frequency and intensity of physical distubance and the rate of sediment accumulation.

The temporal significance of growth interruptions must be determined before their environmental significance can be assessed. Geometry of calicle growth at these surfaces is critical for recognizing the manner in which growth was reestablished. Colonization by the settling of larvae on a dead surface has a much different implication than rejuvenation from surviving calicles. The former could occur on long dead skeletal hardgrounds, and the latter indicates physical disruptions during the life of a single chaetetid. Clay partings and clay-filled calicles record mud burial events resulting in partial mortality, followed by rapid rejuvenation and overgrowth of the sediment. Encrustation of growth-interruption surfaces by auloporid corals, and more rarely bryozoans and stromatolitic algae, indicate prolonged exposure of the skeletal surface and subsequent recolonization. Interestingly, auloporid encrustation appears to be more common in clay-rich carbonates having evidence of more frequent and higherenergy disturbance events. Evidence of dissolution or biocorrosion of the skeletal surface may imply an even longer period of exposure between disturbance and recolonization.

Local development of chaetetid mounds and biostromes also permits larger-scale environmental fluctuations to be recognized. Changes in growth form, typically associated with changes in clay content of the enclosing carbonates, appear to reflect fluctuations in clastic sediment influx and water turbidity. Subtle clay-rich intervals and unconformity surfaces are recognized within chaetetid-bearing units only a few meters thick. The thin sedimentation units thus defined appear to be correlative between outcrops separated by tens of kilometers.

Close examination of spongiomorph and colonial skeletons therefore has the potential to shed light on depositional processes and environmental changes at time scales of tens to thousands of years normally inaccessible to paleoecologists. 